\title{
Conservation science and UNESCO Biosphere Reserves
}

The front section of this issue of SAJS foregrounds a number of items relating to the science of environmental and biological conservation.

We feature an important overview of South Africa's UNESCO Biosphere Reserves by Ruida Pool-Stanvliet and Kaera Coetzer. Many readers may not be familiar with the concept of Biosphere Reserves, nor be aware that they can make an almost unparalleled contribution to sustainability science in South Africa. Although the Man and the Biosphere Programme was launched in 1971, South Africa's first biosphere reserve was declared only in 1998 after the country had been readmitted to UNESCO, consequent upon our becoming a democracy.

Biosphere reserves, of which South Africa currently has 10 - located in six provinces and collectively covering almost one-tenth of the total land area - are eminently appropriate landscape management areas for our age of the Anthropocene. Their purpose is to facilitate, in the most flexible and inclusive manner of governance, many of the global Sustainable Development Goals. In doing so, they ensure long-term conservation and appropriate land use in designated socio-ecological systems that encompass and include many forms of landholding and livelihoods.

Unlike other institutions in South Africa's protected area estate, biosphere reserves are not enforced through legislation, but rely on their success through collaboration, education and interaction with local partners. Our country has a long history of strict forms of nature and wildlife conservation, dating from proscribed hunting areas in the pre-colonial era, to the colonial game reserves of the 19th century in the Cape and Natal colonies and in the Transvaal Republic. The 20th century saw the international acceptance of the idea of national parks and during that century South Africa's national parks proliferated, as did the provincial game reserves. All these, however, have stringent legislation to monitor their activities, and their organisational structures are hierarchical and bureaucratic. The distinction is clear between top-down control of state-protected areas and bottom-up collaboration among all biosphere reserve stakeholders who can introduce appropriate and flexible socioeconomic environmental management.

Biosphere reserves are ideal localities for studies in, and of, indigenous knowledge. An Invited Commentary in this issue by environmental scientist Fortunate Phaka, highlights the value of applying indigenous names and taxonomies to South Africa's biota. A co-author of $A$ Bilingual Field Guide to the Frogs of Zululand ${ }^{1}$ and a PhD student at North-West University and the University of Hasselt, Phaka is taking a molecular approach in his doctoral research to determine the amphibian species used in the South African traditional medicine (muthi) trade. In his contribution in SAJS, Phaka emphasises indigenous taxonomy and explains its scientific merit. In doing so, he underscores the importance of the organising principles of any taxonomic system and the linkages between biological and cultural diversity. He hopes that his work will lead to environmental policy that is socially and ecologically justified. It is worth noting that Phaka will be networking with Professor Peter Taylor, a mammologist with expertise on bats, who holds the South African
Research Chair in 'Biodiversity and Change in the Vhembe Biosphere Reserve' at the University of Venda, thus demonstrating the opportunities for scientific research and collaboration in biosphere reserves, particularly with local communities.

Phaka's work on nomenclature resonates with that of Adrian Koopman, Emeritus Professor of Zulu Studies at the University of KwaZulu-Natal, whose book Zulu Bird Names and Bird Lore is reviewed in this issue by Richard Aitken. Using oral tradition, praise poetry, riddles and games, Koopman links the names and habits of birds to Zulu culture in interesting ways. Sue Nicolson reviews another innovative book on southern African fauna, Dance of the Dung Beetles: Their Role in our Changing World, authored by the unusual disciplinary partnership of Marcus Byrne, an entomologist, and Helen Lunn, a literature and music scholar. ${ }^{2}$ Brian Reilly assesses the multi-authored Livestock Predation and its Management in South Africa: A Scientific Assessment, an exercise to evaluate the state of science around pastoralism and predators $^{3}$, while the large tome that comprehensively, expertly, and beautifully, includes all The Amaryllidaceae of Southern Africa ${ }^{4}$ by Graham Duncan, Barbara Jeppe and Leigh Voigt is reviewed by Brian van Wilgen. The history of natural history in South Africa finds a place with a new biography of early naturalist and explorer, François Levaillant: The First Safari: Searching for François Levaillant by lan Glenn 5 that is reviewed by Richard Dean.

On the subject of significant books, it would be remiss not to draw your attention to A Fossil History of Southern African Land Mammals. ${ }^{6}$ Written by Margaret Avery, currently Honorary Associate of the Iziko South African Museum in Cape Town - and an Associate Editor of the South African Journal of Science - this is a work that has been long awaited and is destined to become an immediate classic. It is reviewed by Richard Klein, an internationally acclaimed palaeoanthropologist at Stanford University.

\section{References}

1. Phaka FM, Netherlands EC, Kruger DHD, Du Preez LH. A bilingual field guide to the frogs of Zululand. Suricata 3. Pretoria: SANBI; 2017.

2. Byrne $\mathrm{M}$, Lunn $\mathrm{H}$. Dance of the dung beetles: Their role in our changing world. Johannesburg: Wits University Press; 2019. https://doi.org/10.1080/003591 9X.2019.1679277

3. Kerley G, Wilson S, Balfour D, editors. Livestock predation and its management in South Africa: A scientific assessment. Port Elizabeth: Centre for African Conservation Ecology, Nelson Mandela University; 2018.

4. Duncan D, Jeppe B, Voigt $L$. The Amaryllidaceae of southern Africa. Pretoria: Umdaus Press; 2016.

5. Glenn I. The first safari: Searching for François Levaillant. Johannesburg Jacana; 2018.

6. Avery DM. A fossil history of southern African land mammals. Cambridge: Cambridge University Press; 2019.

HOW TO CITE:

Carruthers J. Conservation science and UNESCO Biosphere Reserves. S Afr J Sci. 2020;116(1/2), Art. \#7709, 1 page. https://doi.org/10.17159/sajs.2020/7709 